Revista Iberoamericana, Vol. LXIX, Núm. 205, Octubre-Diciembre 2003, 969-983

\title{
ESTRATEGIAS DISCURSIVAS PARA LA CONSTITUCIÓN DE LA IDENTIDAD FEMENINA EN EL ESPACIO NACIONAL CUBANO, 1890-1910
}

\author{
POR \\ Catharina Vallejo \\ Concordia University, Montreal
}

En uno de los períodos claves de la historia de Cuba, desde aproximadamente 1890 hasta 1910, la esfera cultural presenta una convivencia de varias tendencias artísticas e intelectuales, a menudo contradictorias entre sí. La historia política cubana de esa época incluye un vaivén de paz y guerra, independencia y tutela, y estadios intermedios: la celebración del cuarto centenario del “descubrimiento" de América en 1892 (y la publicación de “Autonomismo e Independencia” de Martí), la crisis económica que duró de 1893 hasta 1898, el comienzo de la revolución y la muerte de Martí en 1895, la explosión del Maine y la intervención norteamericana en 1898, la instalación de la República en 1902 (con la Enmienda Platt), y la insurrección de 1906, seguida de una nueva intervención americana. En ese ambiente conviven autonomistas, anexionistas, independentistas y revolucionarios en aparente respeto mutuo, y con sus visiones particulares de lo que sería la "identidad" cubana. Es llamativo sobre todo el que convivieran en los órganos periodísticos noticias sobre una situación política que impactaba de manera tan fuerte en la vida diaria y que eran de tan diversas ideologías en pugna unas con otras, junto con producciones de gran importe artístico y cultural, así como eventos de un diario vivir que continuaba en medio de los trastornos políticos. En febrero de 1895, por ejemplo, el mismo mes en que estalla la revolución martiana, se publica el número especial del Fígaro, dedicado a "La mujer en Cuba"; en mayo de 1902 se celebra la independencia de Cuba con ediciones especiales de muchas publicaciones, y en julio de ese año publica Mercedes Matamoros en Fígaro su conjunto de veinte sonetos controversiales, titulado "El último amor de Safo".

En ese ambiente, y entre una abrumadora presencia de lo político, las tendencias artísticas y culturales incorporan un rezagado y persistente romanticismo (que fomentaba un espíritu independentista), un incipiente y nunca muy madurado realismo/naturalismo (que se concebía como arraigado en la realidad del momento, y dio lugar a varias novelas), y los inicios y la fructificación del modernismo (que buscaba novedades entre lo territorial, lo literario y lo personal) -en medio de una tentativa de capitalismo, la creciente importancia del periodismo y un naciente feminismo. Las producciones discursivas de esa época reflejan y formulan el pensamiento nacional(ista) de Cuba; a través de la alabanza de la lucha y de sus héroes, de los relatos de los eventos históricos, de la poesía y canciones populares, y a partir de perspectivas muy diversas como lo son el paisaje, la Constitución, 
los certámenes de belleza, la salud y la educación, se crean los símbolos nacionales para la memoria colectiva.

Las publicaciones periódicas juegan un papel importante en este proceso, ya que es a través de la diseminación de lo que se nombra y formula que se conceptualizan y se construyen paradigmas de lo que son la “nación” y la “identidad” cubanas (Anderson 80); se trata de un proceso discursivo que se instituye como patriarcal desde su conceptualización (Franco 207), apuntando hacia una homogeneización y univocidad inherentes a la dimensión “simbólica” (en sentido lacaniano) del dominio del orden y la ley característicos de la lengua. Se vislumbra, por parte de la élite intelectual cubana, un intento consciente de mantener la apariencia de una sociedad que laboraba en condiciones normales de unidad y armonía nacionales. ${ }^{1}$ Abundan expresiones de "respetados colegas” y comentarios razonados y sosegados sobre opiniones de periódicos de ideología contraria. Existe cierta medida de durabilidad y continuidad en las prácticas sociales y culturales cubanas a través de una "presencia prolongada de factores humanos de continuidad e integración, sin específica proyección política”, sobre todo del elemento español (Hernández Sandoica, 157). La primera preocupación, y dominio de los hombres, debía ser la lucha por la sobrevivencia nacional. En el ambiente cultural imperaba no solamente lo hispánico sino lo hispánico “viril” y patriarcal. En este estado de cosas, sin embargo, hubieron de perdurar las contradicciones inherentes a esa solidaridad aparente.

Las mujeres participaban en este ambiente literario altamente politizado en dos formas principales. Por un lado, y de manera sutil, exponen la conflictividad que fundamentaba la sociedad, inscribiéndose ellas en la historia y en la sociedad de la nación cubana. Por otro lado, al vaciarse de significado los símbolos que tradicionalmente se asocian con la mujer (la patria, la naturaleza, y la inspiración poética), abrieron un nuevo espacio para la mujer en la modernidad, explicitando los derechos del deseo y del goce corporales por parte de las mujeres. Las dos vertientes discursivas se logran a través de varios recursos de alusión y evocación, y por medio de una poderosa discursivización de la sexualidad (ver al respecto Foucault). Las mujeres contribuyen con artículos, y sobre todo poemas, a las publicaciones periódicas, en ocasiones para órganos de intereses políticos divergentes. Entre las muchas mujeres que participaban de las actividades literarias en $\mathrm{Cuba}^{2}$ hubo por lo menos cinco que se destacan, adherentes a las mismas tendencias artísticas (contradictorias) que sus compatriotas masculinos -aunque en la política todas son independentistas: Aurelia Castillo de González (1842-1920), expulsada de Cuba por algunos años por ser revolucionaria (“patriótica”); Luisa Pérez de Zambrana (1835-1922) (“romántica” y “patriótica”); Juana Borrero (1877-1896); Mercedes Matamoros (1851-1906) y Nieves Xenes (1859-1915). Son de especial interés las tres

\footnotetext{
${ }^{1}$ Lo dicho por Marta Lesmes Albis para la época precursora a la revolución de 1868 vale también para la época anterior a las guerras de independencia de 1895 y aun posteriormente: "El diseño de nacionalidad esbozado por [los] intelectuales comportaba una reflexión en el orden cultural más coherente y armónica que la que logra en un sentido político, donde el espectro de posibilidades se bifurca y no encuentra comunidad de intereses...” (103).

${ }^{2}$ Ver, por ejemplo, los veinticinco nombres que figuran en la segunda edición del Álbum poético fotográfico de escritoras y poetisas cubanas de Domitila García de Coronado, aparecida en 1914.
} 
últimas (sobre todo "modernistas”), ya que a la vez que participan de la abrumadora presencia de lo "patriótico" radicado sobre todo en el romanticismo, también son las que, a través de sus escritos adherentes al modernismo, dirigen el cauce de la identidad femenina hacia la esfera corporal, en sendas que se rebelan contra las normas uniformes de la sociedad. El aporte de las escritoras a la constitución del sujeto cubano (femenino), su identidad y su realidad es de una producción extraordinariamente rica (mayormente de poesía y de ensayo), pero casi completamente ignorada. ${ }^{3}$ El conocimiento de la situación sociopolítica y de su propio ser como cuerpo deseante, revelado en el discurso, apunta a un poder insospechado en la sociedad de su época por parte de las escritoras. Las mujeres laboraban en el espacio externo pero contiguo al canon y la tradición literarias; sus discursos se constituyen en una dialéctica que debate cuestiones sociales de su situación particular. Ya que es a partir de los márgenes que se producen los mayores cambios en las sociedades, esas escritoras desempeñaron un papel significativo en la constitución de su patria.

Para mayor apreciación del aporte de las poetas en esa época de la cultura cubana es importante primero contextualizar la concepción que de la mujer se abrigaba con respecto a la situación nacional. Hacia fines del siglo XIX estaba ocurriendo en Cuba, como parte de un proceso occidental, una transformación en el constructo (constructo social pero ahistórico), que era "la mujer". Esa transformación la concibieron los intelectuales en términos homogéneos y patriarcales -no importaba la vertiente política que presentaban. Las diferencias ideológicas (la política revolucionaria y su proceso modernizante, la ciencia darwinista, la democracia) desaparecieron ante una común perspectiva sobre el papel de la mujer en la sociedad cubana.

En general, el desarrollo feminista sigue las tendencias culturales occidentales del momento, que se centraban sobre todo en su concepción como “ángel del hogar”, en sus deberes hacia la familia, y en la necesidad de su educación -concebida como su "emancipación”- para mejor educar a sus hijos en la casa. Abundan artículos periodísticos sobre “La educación de la mujer” (Manuel Secades, Fígaro, febrero 15, 1903), “El eterno femenino” (Eulogio Horta, Diario de la Marina, noviembre 4, 1904 y Fígaro, octubre 27, 1907), y “La misión y la aptitud de la mujer cubana” (Rómulo Noriega, Diario... agosto $8,1905)$, que repiten la tendencia ideológica dominante y canónica que de la mujer se tenía en occidente en el momento. En el número de Fígaro dedicado a "La mujer en Cuba” (24 de febrero de 1895), Aurelia Castillo de González aún no veía propicio el momento para luchas feministas activas, y de ahí figuró como título de su ensayo: "Esperemos", imperativo inclusivo y plural que perpetúa uno de los deberes impuestos a la vida feminina tradicional: la espera. Al mismo tiempo, sin embargo, Castillo analizó agudamente el

\footnotetext{
${ }^{3}$ De Mercedes Matamoros existen más de docientos poemas no recogidos en volumen; la prosa ensayística de Luisa Pérez de Zambrana tampoco ha sido reeditada en forma de libro. Los estudios críticos escasean a escala alarmante. Se examinará aquí solamente la producción poética y ensayística, ya que no hubo, durante los años en cuestión, novelas escritas por mujeres. Este hecho desconcierta ante la realidad de que entre las primeras novelistas hispanoamericanas figuraron dos mujeres cubanas: la muy reconocida Gertrudis Gómez de Avellaneda y la completamente olvidada Virginia Auber, gallega residente en Cuba y autora de más de una docena de novelas publicadas en la isla entre 1843 y 1858.
} 
dominio de lo masculino en la época en que vivía, fundándolo precisamente en la cultura guerrera, y en el aporte exclusivo del hombre a las batallas militares, único criterio válido en las "remotas edades" que libraban guerras:

\begin{abstract}
de un lado quedaron gobierno, administración, ciencias, artes, comercio, industrias lucrativas, etc. etc., por la poderosa razón de que la guerra no podía estar más que de ese lado, y quien no paga su contribución de sangre, no puede tener voz ni voto en los destinos de la nación, ni hacer cálculos científicos, ni curar, ni comerciar, ni vivir apenas más que para dar vida al hombre, al guerrero. (I, 180)
\end{abstract}

Después, continúa Castillo, la mujer se hizo objeto de lujo y ostentación, y quedó ignorante. Sobre todo a la madre se la consideró como sublime pero, por tanto, “colocada en cierto modo fuera de la órbita social” (I, 180). Ya entonces Aurelia Castillo ha captado dos elementos importantes del análisis de las diferencias genéricas, y de suma relevancia, precisamente, a su propia época y circunstancia; primero, la transformación de las sociedades de guerrera a institucional $-\mathrm{y}$ la consecuente transferencia de poder, de la fuerza al discurso ${ }^{4}$-y, segundo, el proceso simbolizante que sobre la mujer (y especialmente sobre la madre) se efectuaba- y de ahí su colocación extra-histórica. ${ }^{5}$

En Cuba, como en otros espacios políticos, todo el imaginario de la patria fue simbolizado desde siempre a través de la figura espiritual y corporal femenina: es la “madre patria” o la "virgen” pura, limpia y lejos de la corrupción degradadora, como lo fueron la política, la vida pública y la guerra. Este proceso de simbolización femenina, de una aparente unidad, evidencia contradicciones a partir de las perspectivas de género, filosofía, arte, nacionalismo e historia. En una serie de artículos sobre "Mujeres", publicados en Patria, el órgano del Partido Revolucionario Cubano, José Martí definió lo cubano-femenino sobre todo en términos de servicio a la patria-por-hacer, y muchas veces enaltece a las buenas madres que criaron a los hombres que lucharían por ella (V, 15-45). ${ }^{6}$ Esta simbolización de la patria en lo femenino, maternal ("madre y maestra”) o virginal (la amada pura), permite por un lado hacer equivalente el sentimiento que el hombre tiene hacia la mujer y hacia la patria. Un editorial en El Diario de la Marina el 22 de octubre de 1903, titulado "Por la mujer cubana” explica que ambos son "esa clase de sentimientos que florecen en el alma y que se manifiestan, cuando llega el momento, en sacrificios, en abnegaciones y en ternuras...” Sin embargo, es evidente por otro lado que a la hora de la

${ }^{4}$ Este proceso de discursivización que transforma la acción en palabra se reconocía como signo de la civilización. Ya en 1878, aunque prematuramente, el influyente pensador cubano José Fornaris había escrito que "la espada va cediendo su imperio a la palabra: he aquí el supremo progreso del mundo" (9).

${ }^{5}$ Es notable la actualidad de los argumentos de Castillo, si señalamos la discusión que Foucault llevará a cabo sobre la "sangre” (“a reality with a symbolic function”, 147), la transformación de las sociedades ("the force relationships which for a long time had found expression in war,... gradually became invested in the order of political power”, 102), y la primacía que llegó a cobrar el discurso sobre el cuerpo ("Sex... had to be put into words", 32).

${ }^{6}$ Es notable también un discurso martiano de 1889, en el que "Nuestra América" se formula explícitamente como "Madre América” -título con el que casi siempre se edita este discurso (VI, 133-40). 
lucha, los hombres tendrían que hacer una decisión a favor de una u otra, irse a la batalla por la patria o quedarse con la mujer.

Sobre este particular, y al igual que otros escritores, Martí colocaba el interés de la patria por sobre el amor a la mujer -esposa, madre, o novia. Así lo ha formulado desde muy temprana época en dos textos claves al respecto. En Abdala, drama publicado en la Habana el 23 de octubre de 1869, que recurre a la época del imperio griego para mayor impacto simbólico, queda claro que, a pesar de los “¡Cuántos tormentos...! [y] ¡Cuán terrible angustia!” de Abdala (IV, 620), el amor a la patria se sobrepone al amor a la madre. En el poema "Patria y mujer", publicado en México en 1875, y en El Cubano de La Habana en 1888, asimismo se sobrepone la patria, vista como alma y espíritu perdurable, a la mujer, vista como carnal y perecedera: "Y ¿con qué corazón, mujer sencilla, / esperas tú que mi dolor te quiera? / Podrá encender tu beso mi mejilla / pero lejos de aquí mi alma me espera” (XVII, 111-4). Martí juega la eterna oposición cuerpo-alma con la pareja mujer-patria, con la consabida superioridad del espíritu sobre la carne y, de ahí, de la patria sobre la mujer. Ante la patria, la mujer no es igual; al contrario, pierde su calidad de significante simbólico.

Esta relación del hombre frente a la pareja patria-mujer, que como se ve se instituye no como equivalencia sino como oposición exclusiva y reductiva, puede evaluarse desde la perspectiva de la mujer-sujeto frente a "patria” y "hombre”. José Fornaris ya había explicitado en 1878 que para la mujer el esposo tiene primera importancia, aun por sobre la patria: "Antes que tu patria / y tu familia y tu prado, / y tu cielo idolatrado.../ Sí, tu esposo es primero...” (88). Para el hombre, primero la patria; para la mujer, primero el hombre. La mujer, por tanto, desaparece en última instancia del triángulo semántico; no tiene ningún papel en la constitución de la patria, y su valor simbólico queda vaciado de significado, para dejar al hombre y la patria como los exclusivos valores significativos nacionales. ${ }^{7}$

La cualidad “viril”, vista como superior, fue sobrevalorada aun en las escritoras, lo que da lugar a extrañas contradicciones, como la expresada por Julián del Casal. En La Habana Elegante de julio de 1891 describe a Aurelia Castillo de González en términos de un concurso de belleza femenina: "Una estatua de jaspe rosado, coronada de nieve... cierta dulzura femenina... Los labios, color de fresa... y la gracia de una duquesa del siglo dieciocho. Tal es, a vista de pájaro, en lo físico” (230). Por otro lado, Casal continúa diciendo que "[en] cuanto a la moral, [Aurelia Castillo es] lo más próximo a la perfección.... [E]l lector siente latir entre las páginas del libro [Un paseo por Europa], el espíritu varonil de la autora templado para la acción y rebelde al ensueño...” (230, 234). Lo “físico” de Castillo es ultra-femenino según las normas que imperaban, pero ya que ella era mujer capaz y escritora reconocida, debe tener calidades varoniles. ${ }^{8}$ El discurso valorizado era el masculino, guerrero -épico y heroico- como los hombres; por tanto, la

\footnotetext{
${ }^{7}$ ¿Será una calidad general en la constitución de los países, el que en los momentos de formular la identidad se pierde el valor simbolizante que "la mujer" haya proporcionado? Lo mismo sucedió en la República Dominicana a fines del siglo xix. Véase Vallejo.

${ }^{8}$ Notamos de paso que el "Conde Kostia” (seudónimo del escritor cubano Aniceto Valdivia), en su prólogo a Arpas cubanas consideró a Aurelia Castillo como la "Píndaro con sayas" (Fígaro noviembre 6 de 1904; vi).
} 
Musa de Aurelia Castillo “es la Juana de Arco legendaria, cabalgando en blanco bridón, con el estandarte de la Libertad en la diestra y la trompa épica en los labios...” (231). Ya Martí también había apuntado hacia esa otra dimensión de lo femenino, la de inspiración poética, de larga tradición simbólica. Y en un conflicto patriótico, para Martí ese papel también se convierte en nulo: "ni en alma ni en laúd hay ya más cuerda, / que la que el sueño de la patria canta” (“Patria y mujer”, XVII, 113). En la misma lucha patriótica, librada por la pluma, la mujer queda destituida de los simbolizantes patria y musa.

Para la constitución de una identidad femenina histórica (concepto de la modernidad), era necesario anularla como objeto simbólico y de ahí abstracto, fenómeno de larga tradición. Sin embargo, la fundación del sujeto discursivo, es decir, la identidad como escritora o poeta en un espacio histórico particular, era de difícil conquista para las mujeres. En su estudio de escritoras del romanticismo español, Susan Kirkpatrick señala el proceso de la constitución del sujeto durante esa época, cuando se conceptualizó de manera fuerte la separación entre lo privado y lo público, y entre lo interior y lo exterior. El romanticismo promovió la acción de un sujeto individual cuyo mundo era especialmente interno, pero la mujer no se vio como ‘sujeto' de ese mundo articulado en el discurso. Por tanto, "the woman writer who situated herself in any way within Romantic discourse as a writing subject confronted and challenged a basic premise of that discourse, the premise that located women outside subjectivity and the production of meaning” (25). Las mujeres podrían escribir, pero su escritura se conformaría a los mismos parámetros que valían para el ángel del hogar: sentimiento, sacrificio, amor abnegado (92). La lengua constituye la frontera entre lo subjetivo y lo objetivo, y entre lo simbólico y lo real; es el límite material contra el que uno y otro se constituyen dialécticamente (Kristeva 107). La escritura, precisamente, es "the ridge where the historical becoming of the subject is affirmed" (98). Aurelia Castillo advirtió en 1895, sin embargo, que en el proceso civilizador de las culturas, era difícil que la mujer participara de "la palabra”. Subraya el papel silencioso al que todavía estaban forzadas las mujeres cubanas de su época, cuando decían éstas que "aquí estamos aplaudiendo vuestra obra y preparándonos silenciosamente” para recibir lo que habrían conseguido las feministas europeas (I, 182). Las mujeres cubanas que publicaban sobre asuntos nacionales se internaban en terreno vedado y se valieron de estrategias que permitieran, de manera soslayada, la entrada al discurso.

Aun en épocas muy posteriores al 1900, los historiadores de la literatura cubana veían a las poetas como "la mujer escritora", una entidad nebulosa del mismo estatuto abstracto, simbólico y unisémico que "la mujer”. ${ }^{9}$ Estas concepciones niegan la legitimidad histórica del discurso particular y específico de las escritoras cubanas. Las que vivían y escribían en torno al 1900 sí que estaban muy conscientes de que la armonía de la sociedad cubana en busca de la nueva "patria" era aparente y escamoteaba problemas muy serios de diversa índole. Ya removida "la mujer" de los ideologemas patria y musa, podían las mujeres presentar los conflictos en su obra. Este discurso también exterioriza y formula las

\footnotetext{
${ }^{9}$ Escribe Cintio Vitier en 1952 con respecto a Mercedes Torrens (una poeta de entrado el siglo xx) que ésta, "como sucede con casi todas las poetisas que hemos tenido en la República, ...ofrece una poesía que es personal en la medida que es ahistórica” (148); en 1966 Raimundo Lazo opinaba que las poetas "viven y cantan en la vaga intemporalidad en que las confina el aislamiento y las limitaciones que la sociedad tradicional impone a la mujer" (176).
} 
contradicciones de su propia situación genérica y social. Son las mujeres, precisamente, quienes en sus textos exploran las contradicciones cuya ausencia del foro público cubano creó un vacío significativo. De manera sutil y heterogénea aluden a los profundos conflictos que aquejaban a la sociedad. Así como lo expresaran Beverley y Zimmerman, la unidad de un pueblo es fundamentalmente una unidad simbólica, construida en prácticas discursivas en pugna, y de las que participa la expresión literaria como constitutiva de lo social (ix). En Cuba persistía la lucha por aparentar esa unidad simbólica en medio de conflictos reales y profundos, señalados estos últimos en particular por las escritoras. Es a través de las diferencias que se desarrolla el proceso semiótico de significación, constituyendo el lenguaje una red articulada de diferencias que separa los objetos del sujeto y así construye un significado (Kristeva 198). La escritura femenina, situada en el margen de la sociedad, es un espacio de diferencias con el centro hegemónico. La producción de las escritoras, por tanto, constituye un componente altamente significativo en las manifestaciones culturales de su época.

La antología de Domitila García de Coronado (1847-1937) abarca la producción literaria femenina entre 1860 y 1920 a través de sus varias ediciones (1868, 1914, y 1926), y es un ejemplo notable de las estrategias de heterogeneidad utilizadas por las escritoras para revelar su visión de la realidad cubana. Con motivo del regreso de Gertrudis Gómez de Avellaneda a Cuba en 1860, García colecciona composiciones de mujeres poetas cubanas, y las presenta a la poeta coronada, publicando el conjunto en 1868 con textos de catorce poetas y el título de Álbum poético fotográfico de escritoras y poetisas cubanas. ${ }^{10}$ Su primer fin es erigir "pedestales a las cubanas que yacían en el olvido” (García 10). Presenta una breve biografía de cada poeta, pero omite juicios porque quiere limitar "mi cometido a una honrosa exhibición de los frutos de la inteligencia femenina en Cuba” (10). Sin embargo, esa presentación es también una estrategia para insertar comentarios sobre la sociedad y la política de su tiempo, que indican una "diferencia” (generalmente expresada como oposición) de alguna clase -de épocas, de sistemas políticos, de nacionalidad, del poder artístico de las mujeres. El proceso mismo de la producción de la obra -elaborada a través de más de cincuenta años- se inscribe en el quehacer histórico de la sociedad. Por ejemplo, en la edición de 1914 menciona que “ahora” en Cuba hay más de mil obreras en la imprenta (en la biografía de Úrsula Céspedes de Escanaverino; 67); admira al héroe patriótico Carlos Manuel de Céspedes (en la biografía de Aurelia Castillo de González; 135); discurre sobre los “opuestos tipos de la aristocracia soberbia privilegiada y la democracia abnegada y heroica” (en Luisa Pérez de Zambrana, 92); menciona que "éramos todos entonces españoles por el dominio de soberanía, y hoy somos cubanos" (en Sofía Estévez y Valdés de Rodríguez, 176); y menciona que Fermina de Cárdenas de Armas escribió un capítulo de Frasquito (1894), la novela de su marido José de Armas y Céspedes (238). El volumen de García de Coronado es paradigmático de la estrategia de alusión y de inclusión de contrastes que hubieron de practicar las mujeres poetas.

Una serie de poemas publicados por Mercedes Matamoros en Fígaro entre 1897 y 1905 es indicativa de otra de las estrategias alusivas practicadas por las poetas. Los títulos de los poemas a menudo consisten de dos partes; la segunda, entre paréntesis y alusiva a

${ }^{10}$ La última edición refundida tendrá veintisiete poetas, casi todas del siglo XIX. 
la situación concreta y particular de Cuba, apunta a las divisiones que sufren los sectores humanos del país y anula el carácter positivo de la primera parte. De esta manera, por ejemplo, “Los héroes. (Durante la guerra)” (marzo de 1902) lamenta la destrucción causada por una guerra necesaria. Igualmente, la pérdida de las vidas amantes y productivas, acarreando la pobreza, la orfandad y el abandono, es abarcada en "Ángeles errantes. (Durante el bloqueo)” (octubre de 1901). Así también, el contenido de los poemas se confronta con la realidad múltiple y heterogénea. En "La bella entusiasta. Durante la guerra” (fechado 1897, publicado en diciembre de 1904) Matamoros explora los contrastes ofrecidos por la guerra distante. Ésta se hace presente a través de la lectura de un periódico que recuenta las hazañas de "aquel hermano tan querido, / ... / por quien ruegas al cielo noche y día”. La hermana lee a la familia, convocada en el aquí y ahora observados por la voz poética, que también se hace presente a través del vocativo: “...el poder de tu ardiente fantasía / a otros lugares de dolor te arrastra; / a los montes lejanos y sombríos, / ...donde aguarda / rodilla en tierra, con el rifle al hombro, / el insurgente que vigila y calla; / ... / ¡Cómo se pintan en tus negros ojos / las hondas conmociones que te embriagan!” Otro poema llamativo de esta serie es “Caprea. En el bloqueo" (enero de 1904) que, a partir de la palabra latina del título que refiere a la corza (pequeña presa de caza), utiliza los recursos de la alegoría y la oposición para aludir a la situación de Cuba (“dulce presa” de "virgen cubana”) teniendo que pedir "pan y asilo” de "un sátiro ya viejo, de alma perversa”, que “es rico, muy rico, porque en un tiempo / explotó con fortuna la raza negra...” Estos textos de tono y contenido patrióticos señalan al mismo tiempo el costo de la lucha por constituir la patria.

Nieves Xenes por su parte explora los contrastes a través del modo alusivo en su poema "En el álbum de Nena Zayas”, fechado diciembre 1897 que, a pesar del título de poesía ocasional, trata de los contrastes de una sociedad en guerra: “Absorta en las angustias de la patria, / con hondo espanto en ansiedad febril, / escucho, lejos, los ahogados gritos / de los que caen, en la sangrienta lid. / Tú pasas ostentando deslumbrantes / tu juventud, tu gracia y tu beldad / ...” (57). El contraste entre el espanto y la angustia de la guerra por un lado, y la belleza y gracia de la joven por otro, se intensifica al incluir los sentidos del oído (el estruendo de la guerra) y de la vista (la ostentación de la joven). Las mujeres no han participado en la guerra; solo imaginan u oyen la batalla desde lejos, mientras ven la belleza de su país en torno. Los contrastes de su situación son causa de angustia y la expresión de la misma, a través del discurso, revela el conflicto; sus estrategias les permiten adquirir "presencia” e inscribirse en la historia guerrera.

Raimundo Lazo señala el tono polémico y oratorio de la literatura cubana después de 1868 (19), así como el tono oratorio en la producción literaria, no solo en la ensayística sino también en la poética (190). Dadas las circunstancias del momento, es un desarrollo natural y quizás necesario. En efecto, la oratoria toma el lugar de la violencia militar o la conquista por medio de las armas, puesto que se empeña en "conquistar” por medio de la palabra. Era imprescindible el contacto verbal entre los intelectuales y la población, diseminar a partir de la ficción del cuerpo presente los elementos ideológicos que se insertaran en el momento histórico. El recurso que traduce la oratoria en la poesía es la declinación vocativa (ver al respecto Antonio Miguel Bañón), recurso que se hace frecuente en la poesía cubana. Ésta se hace evocativa de las hazañas de los héroes, 
invocativa en las llamadas en favor y auxilio de la causa, y convocativa citando al público a concurrir a los actos patrióticos.

La patria, la nación y otros conceptos corolarios que las conforman (la independencia y la libertad -ambas también explícitamente representadas como femeninas), se formulan como un deseo, y por tanto irrealizado; es una ausencia. El vocativo se instituye como un llamado a esa ausencia irrealizable. Obra como un elemento deíctico que orienta al lector hacia la voz que produce el texto; mantiene el nexo con la "presencia" de la oralidad en un discurso que supone un auditorio en un esfuerzo por adquirir el poder efectivo de la palabra. Los signos de admiración toman el lugar de los cambios en la voz, de las exclamaciones y de los ademanes corporales que acompañarían el discurso oral. Las mujeres adoptan el recurso del modo vocativo; casi todas las poetas acompañan a sus compatriotas masculinos en la alabanza de los héroes de la revolución, y abundan poemas vocativos dedicados a Céspedes, Maceo, Máximo Gómez, Martí y otros, en un tono de tradicional elocuencia. El vocativo en manos de las mujeres poetas se hace también estrategia para referir y exponer los conflictos de la sociedad cubana. En los poemas anteriormente citados ya se ha podido observar el frecuente uso del vocativo. "La bella entusiasta. Durante la guerra” de Matamoros insiste en la presencia de la voz femenina: “...Se oye por fin tu voz!” Ella así contradice el mutismo expresado por Castillo, y señala al mismo tiempo el final de la espera.

Nieves Xenes produce varias composiciones que utilizan el modo vocativo, entre otras “A la niña Otilia Bernal”, un breve poema en el que invoca a la niña que: "sé buena y tierna, perdona y ama. / ¡Y nunca sepas lo que es el odio!” (189). La alusión al odio, tan extraño entre la referencia a los deberes femeninos tradicionales, produce una ruptura, y se aclara solo en el subtítulo del poema: “(Los restos del Maine)”. Los paréntesis, recurso de separación y contraste, recuerdan el uso que hace de ellos Mercedes Matamoros en los títulos de sus poemas. Ésta igualmente refiere al odio en su poema "La muerte del monstruo”, publicado a raíz de las celebraciones de la independencia: “vírgenes, niños, jóvenes y ancianos /.../ y unidos en armónico concierto, . .../ ...porque el Odio ha muerto" (Fígaro mayo 20 de 1902; subrayado en el original). Queda claro en éste, el último verso, que el monstruo del título refiere al rencor que se ha sembrado entre la población cubana durante las largas contiendas entre ideologías opuestas.

Los conflictos señalados por las poetas no se limitan a la guerra. A la edad de sesenta y cinco años, Luisa Pérez de Zambrana publica en 1900 una vehemente apelación “A los legisladores...”, invocando "Al cadalso”, y criticando a la civilización por permitir una práctica de tan "bárbaro tormento" que no conviene a "la moderna edad”, es decir la pena de muerte, que debe producir vergüenza: “...cúbrete el semblante con las manos, /¡oh civilización!” (390). Invoca y convoca a los “iLegisladores de mi joven Cuba!” a que examinen su conciencia y vean las consecuencias de esa práctica en los hijos, madres y viudas de los condenados. Su descripción de la situación del reo y del estado de los familiares es desgarrante (390-2). Las poetas Xenes, Matamoros y Pérez aluden a una nueva invocación de la trillada oposición “civilización y barbarie”, a través del odio y de la pena de muerte, elementos de la barbarie que se oponen a la bondad y el perdón de una sociedad civilizada. Al mismo tiempo queda claro que los elementos de la barbarie, 
potenciados a través del poder ejercido por los legisladores y los jefes de Estado, son masculinos, y los de la civilización, a través del discurso de protesta que los revela, femeninos.

El uso del vocativo por parte de las poetas no solo les confiere legitimación en la imitación de un procedimiento establecido. Los discursos adquieren su significado sobre todo a través de la recepción por parte del que recibe la comunicación (Kristeva 32); por tanto, en la evocación del otro reafirman el yo, y se constituye en sujeto hablante, nueva dimensión pública para la mujer. Su escritura, lejos de ser representación de la sociedad, es producción de discurso y, así, de significado, ideología y poder. El modo literario abre nuevo paso para la mujer cubana, que se permite hablar de la guerra como objeto del discurso, mientras habla a otro como sujeto de ese discurso, dialéctica que se hace, en muchos casos, un interrogatorio acerca de la (f)utilidad de la guerra. Las poetas cruzan la frontera entre lo interior (el hogar, el sentimiento, la ciudad), hacia el exterior (el campo de batalla, el discurso público), y van hacia la guerra, no apropiándose de este terreno tan ostentosamente masculino, sino añadiéndole su propia dimensión. Al insertarse en el discurso en tanto hablante directo, convierten su estatura de simbólica (madre patria, madre de la patria, musa poética), en histórica (poetas de épocas conflictivas). El modo vocativo era un recurso tradicional para los hombres, pero en manos de las escritoras se convierte en significante con significado nuevo. En "La bella entusiasta. Durante la guerra” de Matamoros, la lectura en voz alta por parte de la joven, de representada oratoria, es su manera de inscribirse en la historia, tomando la palabra: “...[su voz,] Suave al principio / cual suspiro de brisa entre las ramas, / parece que a elevarse no se atreve, / por lo que va a decir intimidada, / pero luego va alzándose por grados / como olas por los vientos impulsadas, / y pronto cambia su dulzura en notas / que tu prudente padre se apresura / a encomendarte discreción y calma; / mas no te es dado moderar tu acento..." (Fígaro diciembre 1904). Ya el mandato patriarcal no callará la voz de las mujeres sino cuando es por voluntad propia, como estrategia discursiva de la dialéctica del discurso y sus silencios alusivos.

Así, como parte de la presencia “vocal” las poetas utilizan también la estrategia del silencio, ${ }^{11}$ la falta de explicitación de lo que no se quiere decir. La misma Matamoros publica en abril de 1895 el poema "Incógnita”, otra alegoría referida a Cuba (“virgen pura, vilmente profanada, / juguete del más cruel de los destinos,...”), sin jamás explicitar el referente: “¿Quién es, dime, esa hermosa infortunada / digna de tu pincel y de tu amor?” Un extraordinario poema de la joven Juana Borrero, escrito en 1892, también utiliza el recurso del silencio, la supresión del referente. A partir del título “¡Esperad!”, imperativo que recuerda a Castillo, se dirige en forma de apóstrofe (la interyección vocativa) a los que se sacrificaron por la lucha patria, pero sin jamás mencionarlos directamente. A través del silencio se dirige a los que "descansan en el seno de la patria / que con valor heroico defendieron...”, a los que "quizás nos culpan de mirar pasivos / la agonizante convulsión de un pueblo, / que pugna en vano por romper el yugo...” (68). La espera, pues, es para ellos: “...¡Quizás no tarde / de la batalla entre el confuso estruendo / de ¡Libertad! el

11 "There is not one but many silences, and they are an integral part of the strategies that underlie and permeate discourses” (Foucault 27). 
anhelado grito / en conmover vuestros sagrados restos!” (68). El contraste entre "Nuestros hermanos los que sufren vivos..." y el silencio de los héroes, ausentes en la muerte y en la alusión, abre un inmenso vacío de desgarrador significado acerca de las múltiples ausencias causadas por el conflicto político. En esos poemas los puntos de contacto con elementos significativos de la existencia cubana de esa época son llamativos: la espera, el vacío, el deseo, el imperativo, la contradicción y el contraste.

En los poemas de técnica mayormente descriptiva las poetas también señalan el espíritu conflictivo. En "El juramento” (fechado en 1898, publicado en abril de 1905), Mercedes Matamoros propone la angustia del hombre, “cabecilla” sombría, que recibe un mensajero del enemigo que resulta ser un antiguo amigo; presenta la lucha de la conciencia como mayor que las batallas guerreras: “iningún combate pudiera / con éste nunca igualarse! /.../ para el cruento sacrificio / siente el corazón cobarde /.../ o ser traidor a la Patria / y arrostrar nota de infame, / o condenar al amigo / como verdugo implacable!”. En el momento de dar la orden de liberar al espía, un rayo de luz que cae en la bandera sirve de inspiración y animación al cabecilla y señala el contraste con la muerte de los mártires. En esta guerra, las decisiones se toman para ganarla; el poema termina con la llamada del cabecilla: “¡La ejecución proyectada / ni un momento se dilate! / ¡Hay que atacar el poblado, / compañeros, adelante!” Matamoros se inserta en el campo de batalla, y reformula aquí el trillado campo simbólico hombre-patria-mujer en hombre-patria-amigo, haciéndolo inclusivo de la realidad particular y, de ahí histórico y concreto: en Cuba se trataba de un conflicto en que se enfrentaban y mataban los que habían sido amigos.

La naturaleza, campo de batalla y fuerza reproductora, es elemento poderoso en la constitución de la(s) identidad(es) nacional(es); su metaforización permite alusiones a realidades otras, de valor simbólico. Asimismo, como los simbolizados patria y musa, asume la identidad simbólica femenina de creadora y regeneradora benéfica. Sin embargo, en "Mater Creatoris" (Fígaro, noviembre de 1905), Mercedes Matamoros se aparta del clisé de la madre naturaleza para proponerla como un espacio conflictivo: "A este bello escenario de alegría y dulzura / llegaron dos ejércitos y cruzaron sus armas; / eran, de largo tiempo, defendiendo una idea / o un pedazo de tierra, hermanos que se odiaban...”. Enfatiza el contraste de los sonidos de la vida natural y normal, apacible y alegre (el canto de los pájaros), con el trueno de los cañones guerreros, y concluye con un sentimiento desgarrador: "Oh gran naturaleza, la eterna creadora, / no eres madre del hombre porque no tienes alma”. El dominio del lenguaje, la escritura, se realiza en un espacio separado del estado natural, valor simbólico tradicional de la mujer. También la naturaleza queda vaciada de su valor simbólico tradicional; pero más que una simple desmitificación, por tanto, estos versos de Matamoros constituyen un acto que logra la ruptura de la pareja simbólica de larga tradición, “mujer” y “naturaleza”, y le otorga el poder sobre el discurso propio con una frase que pronuncia sobre el carácter de la existencia humana.

Algunas poetas llevan a cabo otro tipo de búsqueda para la constitución de una nueva identidad para las mujeres, lejos de los conflictos políticos y militares, para centrarse en los conflictos que integraban la constitución de la identidad femenina personal y social. El modernismo (tema polémicamente discutido en la literatura periodística de la época) se vio rebelde ante el dominio de las manifestaciones patrióticas. Apunta Tina Escaja que en Cuba "la búsqueda de una expresión personal resultó particularmente compleja en [las 
poetas de la época] por coincidir los postulados renovadores del modernismo con las definiciones de nación y patria en plena contienda por la emancipación territorial” (Escaja 61). Algunas poetas, sin embargo, entraron en este campo nuevo semántico, creándolo como se estaba creando la patria.

El conocido poema de Juana Borrero, “Las hijas de Ran” (fechado 1891 o 1892), celebra la vida despreocupada y libre de las ondinas del mar (Escaja 79). Borrero se queda en el ambiente mitológico de las ondinas, distancia que por lejana y ahistórica hace aceptable el contenido novedoso; Nieves Xenes, sin embargo, que ya en 1884 había publicado poemas de gran atrevimiento sobre una pasión amorosa desenfrenada e incontenible, se centra en las mujeres cubanas de su sociedad y época. La composición “Boudoir” de 1895 (presentada en el Fígaro de junio 23 de 1895 con grabado de corsé, florero y cama) es particularmente llamativo por su procedimiento alusivo a las posibles actividades llevadas a cabo en el boudoir: "Del arte y la riqueza los primores, / blancas cortinas de ligero encaje, / caprichoso y magnífico mueblaje / de oro y seda de vívidos colores. /.../ Yacen en un diván dorado y grana / un libro, y un corsé blanco y esbelto, / y en un búcaro azul, muere una rosa” (Xenes 93). En "Baño de mar" (fechado septiembre de 1901; 138), Xenes celebra directamente el cuerpo femenino jugueteando en el mar y con el vestido pegado al cuerpo mojado y hermoso. En agosto de 1905 publica "La pasión”, que refiere a la mujer: "Cuando el amor la embriaga y la enloquece, / de fiebre devorante en el exceso, / el ansia que la abrasa y la estremece / al hambre de la fiera se parece...” (141). En 1907, Xenes gana el premio del certamen de los Juegos Florales con su poema "Julio", que erotiza el paisaje cubano de una manera inaudita:

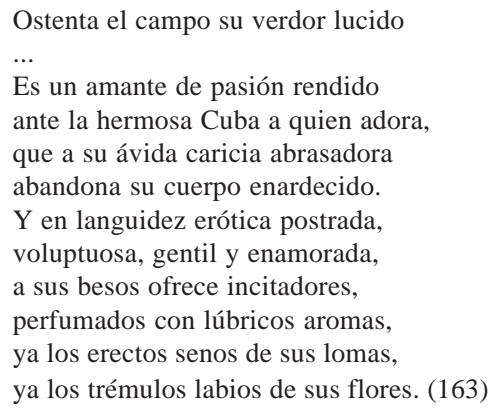

Con Mercedes Matamoros, quien niega significación simbólica a la Mater creatoris, Xenes transforma los valores que se le han otorgado a la tradicional conceptualización femenina de "naturaleza” para invertir los valores simbólicos: ahora el paisaje metaforiza el cuerpo deseante de la mujer.

También Xenes y Matamoros se construyeron, a través del discurso, una identidad subjetiva de cuerpo deseante. Era raro el que a la mujer blanca se la presentara en aras del deseo; ${ }^{12}$ la identidad femenina pocas veces se construía en torno a su sexualidad. De ahí

${ }^{12}$ La "cubanidad” siempre fue "imaginada” en términos no solo masculinos, sino también de hombre blanco hispánico, y hubo un general escamoteo de la cuestión racial hasta principios del siglo xx. 
que una poesía que expresa el deseo femenino por parte del sujeto femenino represente una ruptura tan vasta en este ambiente de "protestas verbales de nacionalismo y autonomía...” (Lazo, 210). Primero Xenes y luego Matamoros, ésta sobre todo en su serie de sonetos titulada "El último amor de Safo"13 publicada en Fígaro en 1902, se expresaron en vehemencia subjetiva personal jamás vista en pluma de mujer. El segundo soneto de la serie de Matamoros lleva el título significativo de "Yo": "Mi cuerpo es una sierpe tentadora / y en el mórbido seno se doblega / lánguidamente el cuello como un lirio..."14 Ya no son ondinas, ni un paisaje nacional, sino un sujeto deseante, una yo. En "La bestia" (Soneto XVII) se atreve a igualar la pasión del sujeto Safo hacia Faón a la de dos leones: “¿No escuchas a lo lejos al sombrío / león, que con rugido apasionado / responde a la leona, en el callado / y hondo recinto de su amor bravío? // ¡Amémonos así!....” (21). ${ }^{15}$ Las rupturas inesperadas de la sintaxis en los encabalgamientos añade a la dimensión de vehemencia y violencia. Las referencias a una Safo (de tiempos remotos cuasi mitológicos) se concretiza a partir del discurso vocativo. El primer soneto de la serie establece de inmediato la subjetividad discursiva al dirigirse “Safo a Faón”, explícitamente a través de la "lira”, la palabra poética, “ique es en mis manos la vibrante lira, / flor que se abre, llama que chispea, / onda que ruge, cisne que suspira...!” (13). Son éstas alusiones extraordinarias a imágenes sensuales y hasta eróticas, apasionadas, sobre el poder de la palabra poética que anticipan con mucho a las poetas canónicas del modernismo, y cuya lira dista en concepción fundamental de la épica que Casal vio en Castillo o la musa abstracta de Martí.

En conclusión, en estos textos de unas pocas poetas cubanas que trabajaban en una época de grandes trastornos políticos se ha podido ver cómo luchan los ideales patrióticos con los deseos personales y la expresión artística. Se percibe una codificación múltiple y heterogénea que soslaya la homogeneidad que los padres de la patria y el discurso hegemónico querían imponer entre los conflictos que fundamentaban la vida cubana. Estos poemas son manifestaciones de una subjetividad femenina moderna heterogénea que incorpora la dimensión femenina en el ambiente de la Cuba de los años 1890-1910, modernizante y contradictoria. Se desarman los valores femeninos simbólicos tradicionales adscritos a la patria, la musa, y la naturaleza. Mediante los recursos de la alusión, el vocativo, el silencio, la expresión apasionada -recursos expresivos heterogéneos y hasta contradictorios-apuntan a los contrastes y conflictos de la sociedad y la historia cubanas, y buscan la afirmación de su propio ser femenino.

Como lo indica Kutzinski, "race [...] is an ideological construct capable of operating independently of physical appearance" (109). Precisamente, "one of the discursive effects of white masculine power is the 'blackening' of the female body in the process of sexualizing it” (118).

${ }^{13}$ Para un acercamiento a este conjunto poético extraordinario, véase Romeu, quien insiste en que Matamoros "merece la atención de la critica feminista" (67).

${ }^{14}$ Algunos de estos poemas presagian los de la uruguaya Eugenia Vaz Ferreira (1875-1924), una de las pocas poetas reconocidas del modernismo hispanoamericano.

${ }^{15}$ Manuel Márquez Sterling, editor de El Fígaro, invitó a Matamoros a leer las composiciones de "El último amor de Safo" en el Ateneo. Al negarse ella por su estado de salud, las leyó él mismo, pero omitió el soneto "La bestia”, “ante el temor de alarmar a las señoras” (carta de Matamoros, publicada en Fígaro de septiembre 2 de 1906 a raíz de su muerte; énfasis en el original). 
Anderson, Benedict. Imagined Communities: Reflections on the Origin and Spread of Nationalism. London: Verso, 1991.

Bañón, Antonio Miguel. El vocativo. Propuestas para su análisis lingüístico. Barcelona: Octaedro, 1993.

Beverley, John y Marc Zimmerman. Literature and Politics in the Central American Revolutions. Austin: University of Texas Press, 1990.

Caballero, Armando O. La mujer en el 95. La Habana: Gente Nueva, 1982.

Casal, Julián del. Crónicas habaneras. Ángel Augier, comp. e intro. La Habana: Universidad Central de las Villas, 1963.

Castillo de González, Aurelia. Escritos. 5 tomos. La Habana: Impr. El siglo XX de Aurelio Miranda, 1913.

Escaja, Tina, “Autoras modernistas y la (re)inscripción del cuerpo nacional”. Sexualidad y nación. Daniel Balderston,ed. Pittsburgh: IILI, 2000. 61-75

Fornaris, José. El arpa del hogar. París: Impr. H. Lutier, 1878.

Foucault, Michel. The History of Sexuality. An Introduction. Vol. I. [1976] Robert Hurley, trad. New York: Random House, 1990.

Franco, Jean, “The Nation as Imagined Community”. The New Historicism. H. Aram Veeser, ed. New York: Routledge, 1989. 204-12.

García de Coronado, Domitila. Álbum poético y fotográfico de escritoras y poetisas cubanas, escrito en 1868 para la señora doña Gerturis Gómez de Avellaneda. Reproducción de la tercera edición... comenzada en 1914. La Habana: Impr. de "El Fígaro”, 1926.

Hernández Sandoica, Elena. “Cuba en el período intersecular: Continuidad y cambio”. 1898: su significado para Centro-América y el Caribe. ¿Cesura, cambio, continuidad? Walter Bernecker, ed. Frankfurt: Vervuert, 1998. 153-70.

Kirkpatrick, Susan. Las Románticas. Women Writers and Subjectivity in Spain, 18351850. Berkeley: University of California Press, 1989.

Kostia, Conde [Aniceto Valdivia], (ed. y pról.). Arpas cubanas. La Habana: Impr. de Rambla y Bouza, 1904.

Kristeva, Julia. The Kristeva Reader. Toril Moi, ed. New York: Columbia University Press, 1986.

Kutzinski, Vera M. Sugar's Secrets. Race and the Erotics of Cuban Nationalism. Charlottesville: University Press of Virginia, 1993.

Lazo, Raimundo. Historia de la literatura cubana [1966]. México: Dirección general de publicaciones, 1971.

Lesmes Albis, Marta. Estado de alma en las Antillas. La Habana: Letras Cubanas, 2001. Martí, José. Obras completas. 27 tomos. La Habana: Ciencias Sociales, 1975.

Matamoros, Mercedes. Sonetos. [El último amor de Safo]. Prólogo de Manuel Márquez Sterling. La Habana: Impr. de "El Fígaro", 1902.

Romeu, Raquel. Voces de mujeres en las letras cubanas. Madrid: Verbum, 2000. 57-68. 
Vallejo, Catharina. Las madres de la patria y las bellas mentiras. Imágenes de la mujer en el discurso nacional literario de la República Dominicana. 1844-1899. Miami: Universal, 1999.

Vitier, Cintio. Cincuenta años de poesía cubana. 1902-1952. La Habana: Dir. de Cultura del Ministerio de Educación, 1952.

Xenes, Nieves. Poesías. Prólogo de Aurelia Castillo de González. La Habana: Impr. del siglo XX de Aurelio Miranda, 1915. 